\title{
APPLICATION OF SSSC TO THE 330kV NIGERIAN TRANSMISSION NETWORK FOR VOLTAGE CONTROL
}

\author{
G. A. Adepoju ${ }^{1}$, M. A. Sanusi2,"*and M. A. Tijani ${ }^{3}$ \\ 1 Dept. of Electronic and Electrical Engr., Ladoke AKintola Univ. of TeChnology Ogbomoso, NiGERIA \\ 2,3 Department of Electronic and Electrical Engr., Federal Polytechnic Ede, Ede, Osun State Nigeria \\ E-mail addresses: 19aadepoju@lautech.edu.ng ${ }^{* 2}$ sanusimufutau@yahoo.com \\ 3muhammedtijani@gmail.com
}

\begin{abstract}
Longitudinal power systems of Nigerian $330 \mathrm{kV}$ transmission network have steady-state problems of congestion, voltage limit violation and high active power loss. Static Synchronous Series Compensator (SSSC) currently in use for solving problems in mesh power systems has not been applied to Nigerian $330 \mathrm{kV}$ power network. This work involves the use of SSSC for solving problems associated with Nigerian $330 \mathrm{kV}$ longitudinal power network using voltage magnitude as performance metrics. Steady state modeling of power system and SSSC modeling produced two sets of non-linear algebraic equations that were solved simultaneously using Newton-Raphson algorithm (NR) method and was implemented using MATLAB. Results of power flow analysis of Nigerian $330 \mathrm{kV}$ transmission network without SSSC showed that, there was voltage limit violation of $\pm 10 \%$ at bus 16 Gombe (0.8973p.u). However, the results with incorporation of SSSC showed that, the SSSC was effective in eliminating voltage limit violation, control bus voltage magnitude to specified value (bus 14 from 0.9462p.u. to 1.00p.u.) and reduced network active power loss by more than $5 \%$ of base case ( $93.87 \mathrm{MW}$ ). Therefore, SSSC is effective in solving steady-state problems of longitudinal power systems.
\end{abstract}

Keywords: Longitudinal, Mesh, Newton-Raphson, SSSC modeling.

\section{INTRODUCTION}

The economic development and social changes around the world are driven by availability of electricity. The supply of this electricity involves a large interconnection of generating sources and customer loads through a transmission system network that consists of transmission lines, transformers and other ancillary equipment $[1,2]$. These transmission systems are either mesh or longitudinal in nature.

The transmission facilities in power systems provide equal access for power evacuation to all participants at all times, ensure full capability and reliability at minimum technical loss and ensure equitable load allocation to consumers. The power transferred through a transmission network is a function of transmission line impedance. Low transmission line impedance enables larger power flow while high impedance limits the flow of electricity [3].

Longitudinal transimission systems such as Nigerian transmission system have high impedance and are characterised by various steady-state operational problems such as congestion, high transmission line losses, voltage limit violations, loss of system stability and inability to utilise transmission line capacity up to their thermal limits $[4,5]$. These problems have been reduced by reinforcement of generating station and transmission line; building new power plants and transmission lines as well as using traditional electromechanical devices. However, long construction time, high cost of implementation and regulatory pressure hinder the reinforcement of transmission lines and generation stations while low speeds, mechanical wear and tear limit the use of electromechanical devices [6].

The use of Flexible Alternating Current Transmission System (FACTS) Controllers with fast responses and no major alterations to the system layout are increasingly replacing electromechanical devices. FACTS devices are power electronic devices or other static controllers incorporated in AC transmission systems to enhance controllability and increase power transfer capability [7]. SSSC is a FACTS controller that belongs to the Voltage Source Converter (VSC) series connected FACTS family. It opens up new opportunities to control 
the current and power flow over designated transmission lines in order to increase their deployment, increase usable transmission capacity of lines and reduce the need for construction of new transmission lines. It also provides dynamic reactive power support and improve voltage profile [8].

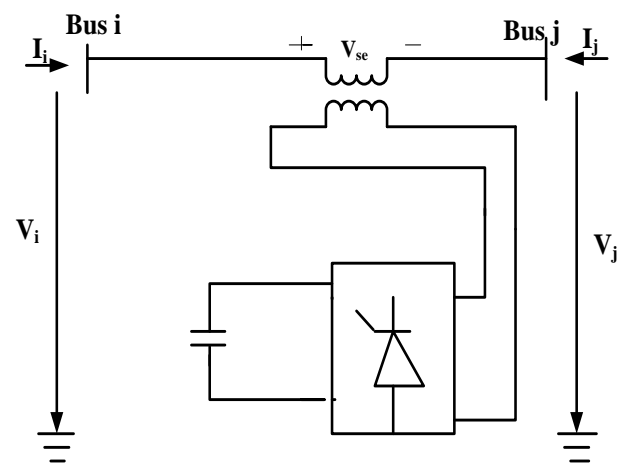

Figure 1: SSSC Operation Principles [9] inadequate required fund to regulate, update, modernize, maintain and expand the network, $[5,12]$.

\section{POWER FLOW PROBLEM FORMULATION AND EQUATIONS}

The Power flow calculation is one of the most fundamental components in the analysis of power systems and is the cornerstone for almost other tool used in power systems simulation and management. Power flow problem involves solving a set of non-linear algebraic equations which represent the network under steady state conditions [14]. The power flow equation can be written in general form.

$$
\sum_{k} Y_{i k} V_{k}+Y_{i}^{s h} V_{i}=\frac{S_{i}^{*}}{V_{i}^{*}}
$$

Where $Y_{i k}=$ the admittance matrix, $Y_{i}^{s h}=$ the bus shunt admittance, $\mathrm{V}_{\mathrm{i}}=$ the specified voltage at bus $i$ and $S_{i}=$ the bus power injection which represents constant power loads and generators.

\subsection{Operating Principle of SSSC}

$$
I_{i}=V_{i} \sum_{j=0}^{n} y_{i j}-\sum_{j=1}^{n} y_{i j} V_{j} \quad j \neq i
$$
capacitor in series with a transmission line through the coupling transformer as shown in Figure 1 [9]. In principle, SSSC can generate and insert a series voltage, which can be heal and reactive power at bus $i$ is regulated to change the reactance of the transmission line in order to control the power flow of the transmission line or the voltage of the bus, to which SSSC is connected.

\subsection{Nigerian 28-Bus 330kV Transmission System}

The power stations in Nigeria are mainly hydro and thermal plants managed by Independent Power Project (IPP) and Generation Company (GENCO) private participating partners. The Nigerian national grid is an interconnection of $9,454.8 \mathrm{~km}$ length of $330 \mathrm{kV}$ transmission lines with nine power stations as shown in Figure 2. These generating stations are sometimes connected to load centres through very long, fragile and radial transmission lines, which are prone to frequent system collapse [10]. The grid interconnects these power stations with twenty eight buses and fifty two transmission lines of either dual or single circuit lines and has four control centres (one national control centre at Oshogbo and three supplementary control centres at Benin, Shiroro and Egbin [11].

The maximum transmission capacity of Nigerian transmission system is about 4,000 MW and it is technically weak, therefore very sensitive to major disturbances. The challenge of this major disturbances have been in existence for a very long time with some identified problems such as its wheeling capacity that is far below the required national needs, the technologies used generally deliver very poor voltage stability and profiles. There is also regular vandalization of the lines, associated with low level of surveillance and security on all electrical infrastructures with $P_{i}+j Q_{i}=V_{i} I_{i}^{*}$

$$
I_{i}=\frac{P_{i}-j Q_{i}}{V_{i}^{*}}
$$

Substituting for $I_{i}$ in equation (3) yields

$$
\frac{P_{i}-j Q_{i}}{V_{i}^{*}}=V_{i} \sum_{j=0}^{n} y_{i j}-\sum_{j=1}^{n} y_{i j} V_{j} \quad j \neq i
$$

Separating the real and imaginary parts

$$
\begin{array}{r}
P_{i}=\sum_{j=1}^{n}\left|V_{i}\right|\left|V_{j}\right|\left|Y_{i j}\right| \cos \left(\theta_{i j}-\delta_{i}+\delta_{j}\right) \\
Q_{i}=-\sum_{j=1}^{n}\left|V_{i}\right|\left|V_{j}\right|\left|Y_{i j}\right| \sin \left(\theta_{i j}-\delta_{i}+\delta_{j}\right)
\end{array}
$$

Expanding (6) and (7) in Taylor's series about the initial estimate and neglecting all higher order terms results in a set of linear equations [12]. These equations can be written in matrix form after linearization as

$$
\left[\begin{array}{l}
\Delta P \\
\Delta Q
\end{array}\right]=\left[\begin{array}{ll}
J_{1} & J_{2} \\
J_{3} & J_{4}
\end{array}\right]\left[\begin{array}{c}
\Delta \delta \\
\Delta|V|
\end{array}\right]
$$

\subsection{Steady State Power Injection Model (PIM) of SSSC}

An equivalent circuit of the SSSC shown in Figure 3 can be derived based on the operation principle of the SSSC where $V_{s e}$ is a voltage source in series with transformer impedance. In the operation of SSSC, $V_{s e}$ can be regulated to control the power flow of line $i-j$ or the voltage at bus $i$ or $j$. In the equivalent circuit $V_{s e}=$ $V_{s e}<\theta_{s e}, V_{i}=V_{i}<\theta_{i}, V_{j}=V_{j}<\theta_{j}$ 


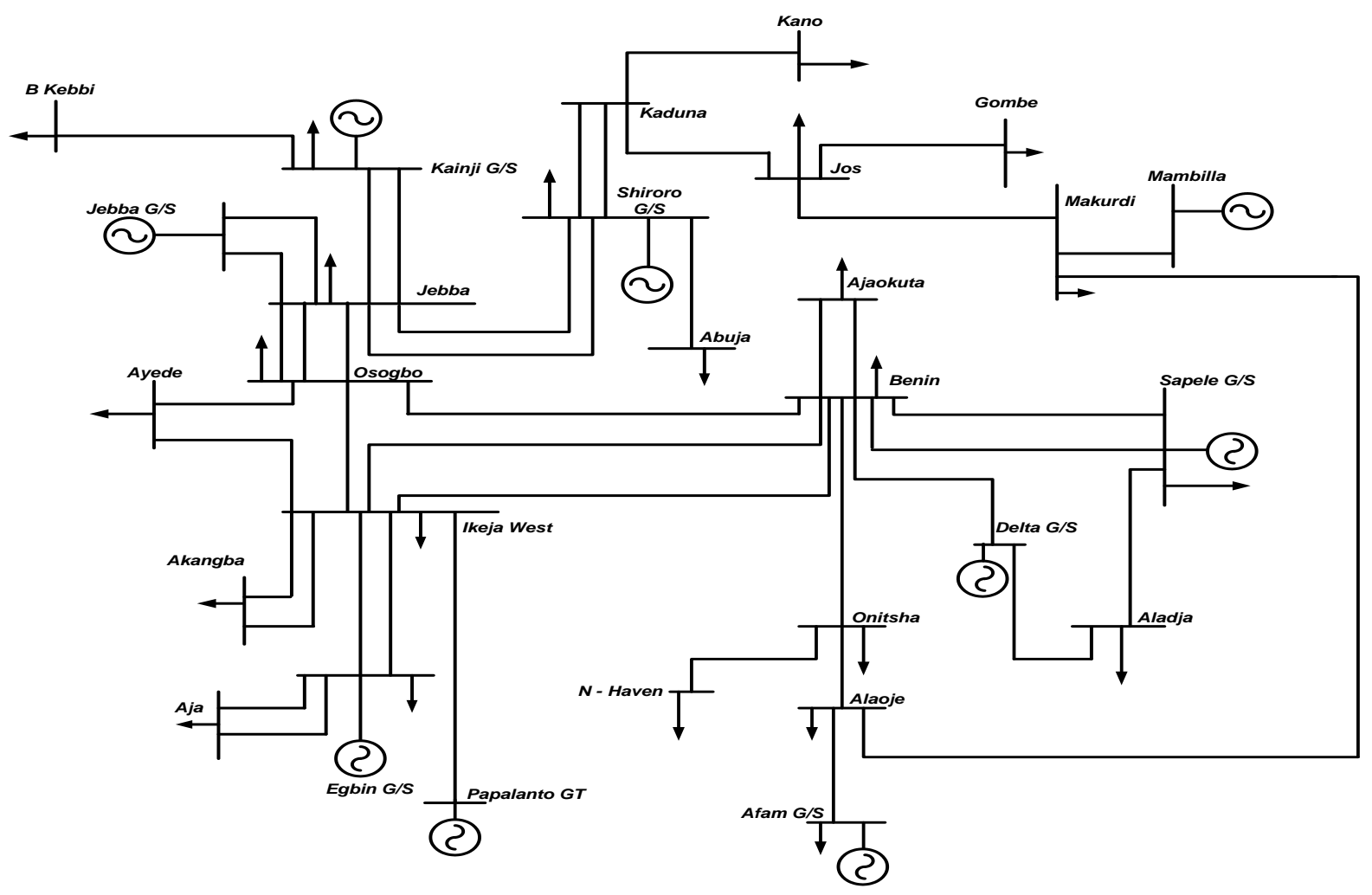

Figure 2: 28-bus Nigerian Power System Networks [13].

The modified power flow equations with SSSC are:

I . Nodal power flow equation at bus i with SSSC

$$
\begin{aligned}
P_{i j}=V_{i}^{2} g_{i i}-V_{i} & V_{j} \\
& \left(g_{i j} \operatorname{Cos} \theta_{i j}+b_{i j} \operatorname{Sin} \theta_{i j}\right) \\
& -V_{i} V_{s e}\left(g_{i j} \operatorname{Cos}\left(\theta_{i}-\theta_{s e}\right)\right. \\
& +b_{i j} \operatorname{Sin}\left(\theta_{i}-\theta_{s e}\right) \\
Q_{i j}=-V_{i}^{2} b_{i i}-V_{i} & V_{j}\left(g_{i j} \operatorname{Sin} \theta_{i j}+b_{i j} \operatorname{Cos} \theta_{i j}\right) \\
& -V_{i} V_{s e}\left(g_{i j} \operatorname{Sin}\left(\theta_{i}-\theta_{s e}\right)\right. \\
& +b_{i j} \operatorname{Cos}\left(\theta_{i}-\theta_{s e}\right)
\end{aligned}
$$

ii. Nodal power flow equation at bus $\mathrm{j}$ with SSSC

$$
\begin{aligned}
P_{j i}=V_{j}^{2} g_{j j}-V_{i} & V_{j}\left(g_{i j} \operatorname{Cos} \theta_{j i}+b_{i j} \operatorname{Sin} \theta_{j i}\right) \\
& +V_{j} V_{s e}\left(g_{i j} \operatorname{Cos}\left(\theta_{j}-\theta_{s e}\right)\right. \\
& \left.+b_{i j} \operatorname{Sin}\left(\theta_{j}-\theta_{s e}\right)\right) \\
Q_{j i}=-V_{j}^{2} b_{j j}- & V_{i} V_{j}\left(g_{i j} \operatorname{Sin} \theta_{j i}-b_{i j} \operatorname{Cos} \theta_{j i}\right) \\
& +V_{j} V_{s e}\left(g_{i j} \operatorname{Sin}\left(\theta_{j}-\theta_{s e}\right)\right. \\
& \left.-b_{i j} \operatorname{Cos}\left(\theta_{j}-\theta_{s e}\right)\right)
\end{aligned}
$$

It can be noted that equation (9) can be written as $P_{i j}=V_{i}^{2} g_{i i}-V_{i} V_{j}\left(g_{i j} \operatorname{Cos} \theta_{i j}+b_{i j} \operatorname{Sin} \theta_{i j}\right)-P_{i j}^{S S S C}$

Where:

$$
\begin{aligned}
P_{i j}^{S S C C}=-V_{i} V_{s e} & \left(g_{i j} \operatorname{Cos}\left(\theta_{i}-\theta_{s e}\right)\right. \\
& \left.+b_{i j} \operatorname{Sin}\left(\theta_{i}-\theta_{s e}\right)\right)
\end{aligned}
$$

Where $P_{i j}^{S S S C}$ represents active power injection of the SSSC voltage source at node i. The other terms in equation (13) take account of the real power contribution at node i as passive two node components.

\subsection{Bus Voltage Control}

In this mode, the series injected voltage is regulated to maintain the transmission line voltage at the point of connection to specified value, i.e.,

$$
V_{i}-V_{i}^{\text {spec }}=0 \text { or } V_{j}-V_{j}^{\text {spec }}=0
$$

Where $V_{i}^{\text {spec }}$ and $V_{j}^{\text {spec }}$ are the bus voltage control references.

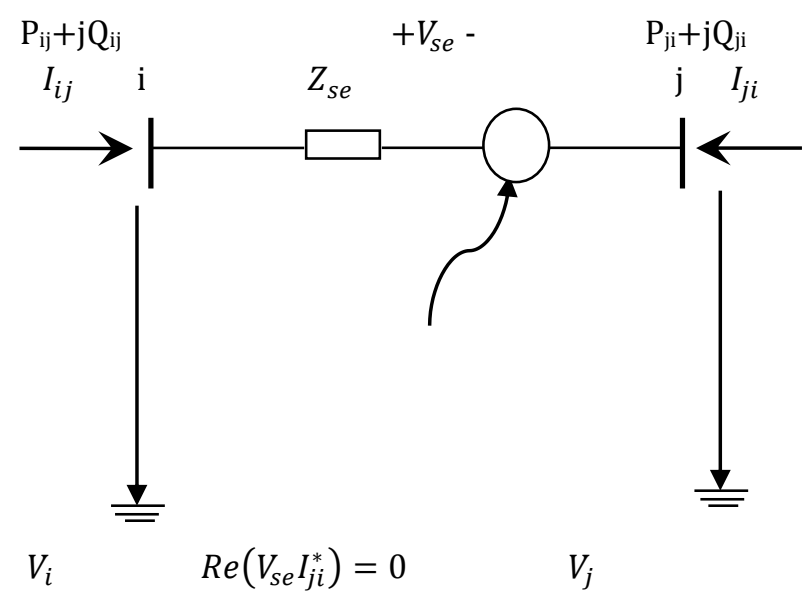

Figure 3: SSSC Equivalent Circuits [9]

\subsection{Series Voltage Control}

The converter generates a fixed series injected voltage magnitude and phase angle, i.e;

$$
V_{s e}-V_{s e}^{\text {spec }}=0 \text { or } \theta_{\text {se }}-\theta_{\text {se }}^{\text {spec }}=0
$$




\subsection{Voltage and Current Constraints of SSSC}

The equivalent voltage injection $V_{s e}$ bound constraints are as follows:

$$
0 \leq V_{s e} \leq V_{s e}^{\max } \text { and }-\pi \leq \theta_{s e} \leq \pi
$$

where $V_{s e}^{\max }$ is the voltage rating of $V_{s e}$ which may be constant, or may change slightly with changes in the DC bus voltage, depending on the inverter design. In principle, $\theta_{s e}$ can be any real phase angle. The current through each series converter should be within its current rating:

$$
I_{s e} \leq I_{s e}^{\max }
$$

Where $I_{s e}^{\max }$ is the maximum current rating of the series converter:

$$
I_{s e}=\left|I_{s e}\right|<\theta_{s e}=\frac{V_{i}-V_{s e}-V_{j}}{Z_{s e}} ; \quad I_{S e}=I_{j i}
$$

The modification of Newton-Raphson power flow algorithm with simultaneous solution of power flow constraints and power flow control constraints of the SSSC are expresssed by equation (19) as follows:

$$
\left[\begin{array}{cc}
H & N \\
K & I
\end{array}\right]\left[\frac{L}{M}\right]=\left[\frac{R}{S}\right]
$$

Where

$$
\begin{gathered}
H=\left[\begin{array}{cc}
\frac{\partial F}{\partial \theta_{s e}} & \frac{\partial F}{\partial V_{s e}} \\
\frac{\partial P E}{\partial \theta_{s e}} & \frac{\partial P E}{\partial V_{s e}}
\end{array}\right] ; N=\left[\begin{array}{cccc}
\frac{\partial F}{\partial \theta_{i}} & \frac{\partial F}{\partial V_{i}} & \frac{\partial F}{\partial \theta_{j}} & \frac{\partial F}{\partial V_{j}} \\
\frac{\partial P E}{\partial \theta_{i}} & \frac{\partial P E}{\partial V_{i}} & \frac{\partial P E}{\partial \theta_{j}} & \frac{\partial P E}{\partial V_{j}}
\end{array}\right] \\
K=\left[\begin{array}{cc}
\frac{\partial P_{i}}{\partial \theta_{s e}} & \frac{\partial P_{i}}{\partial V_{s e}} \\
\frac{\partial Q_{i}}{\partial \theta_{s e}} & \frac{\partial Q_{i}}{\partial V_{s e}} \\
\frac{\partial P_{j}}{\partial \theta_{s e}} & \frac{\partial P_{j}}{\partial V_{s e}} \\
\frac{\partial Q_{j}}{\partial \theta_{s e}} & \frac{\partial Q_{j}}{\partial V_{s e}}
\end{array}\right] ; I=\left[\begin{array}{llll}
\frac{\partial P_{i}}{\partial \theta_{i}} & \frac{\partial P_{i}}{\partial V_{i}} & \frac{\partial P_{i}}{\partial \theta_{j}} & \frac{\partial P_{i}}{\partial V_{j}} \\
\frac{\partial Q_{i}}{\partial \theta_{i}} & \frac{\partial Q_{i}}{\partial V_{i}} & \frac{\partial Q_{i}}{\partial \theta_{j}} & \frac{\partial Q_{i}}{\partial V_{j}} \\
\frac{\partial P_{j}}{\partial \theta_{i}} & \frac{\partial P_{j}}{\partial V_{i}} & \frac{\partial P_{j}}{\partial \theta_{j}} & \frac{\partial P_{j}}{\partial V_{j}} \\
\frac{\partial Q_{j}}{\partial \theta_{i}} & \frac{\partial Q_{j}}{\partial V_{i}} & \frac{\partial Q_{j}}{\partial \theta_{j}} & \frac{\partial Q_{j}}{\partial V_{j}}
\end{array}\right] \\
l=\left[\begin{array}{l}
\Delta \theta_{i} \\
\Delta \theta_{i} \\
\Delta V_{s e}
\end{array}\right], \quad M=\left[\begin{array}{c}
-\Delta P_{i} \\
\Delta \theta_{j} \\
\Delta V_{j}
\end{array}\right], R=\left[\begin{array}{c}
-\Delta F \\
\Delta P E
\end{array}\right], S=\left[\begin{array}{c}
\Delta P_{j} \\
-\Delta Q_{j}
\end{array}\right]
\end{gathered}
$$

Where F in this case is $P_{j i}$ of SSSC, two rows and two columns are added in the usual Jacobian of NewtonRaphson power flow.

\subsection{Modified Newton-Raphson Algorithm for SSSC Controller}

The following are the steps involved in the application of SSSC in Newton-Raphson based power flow of power system network and where the Jacobian matrix and power mismatch equation of Newton-Rapshon solution method have been modified as presented in the flowchart shown in Figure 4.

\section{RESULTS}

Test case 1: Base Case of Nigerian 28-bus system. The results of power flow analysis of the base case of Nigerian 28-bus $330 \mathrm{kV}$ transmission system in Table 1 , shows the voltage limit violation at bus 16 (Gombe) while at buses 9 (Ayede), 13 (New-Haven), 14 (Onitsha), 19 (Jos) and 22 (Kano) the voltage magnitude are lower than 1.0 p.u but within acceptable limits of $\pm 10 \%$ and the overall active power system loss is $93.87 \mathrm{MW}$.

Table 1: Nigerian 28-bus network Voltage Magnitudes and Phase Angle without SSSC

\begin{tabular}{clccc}
\hline $\begin{array}{c}\text { Bus } \\
\text { No }\end{array}$ & Bus Name & $\begin{array}{c}\text { Bus } \\
\text { Type }\end{array}$ & $\begin{array}{c}\text { Bus Voltage } \\
\text { Magnitude } \\
\text { (p.u.) }\end{array}$ & $\begin{array}{c}\text { Phase } \\
\text { angle } \\
\text { (degree) }\end{array}$ \\
\hline 1 & Egbin GS & Swing & 1.0500 & 0.0000 \\
2 & Delta & PV & 1.0500 & 11.9232 \\
3 & Aja & PQ & 1.0449 & -0.2835 \\
4 & Akangba & $\mathrm{PQ}$ & 1.0118 & 0.6501 \\
5 & Ikeja West & $\mathrm{PQ}$ & 1.0193 & 1.0793 \\
6 & Ajaokuta & $\mathrm{PQ}$ & 1.0358 & 6.1814 \\
7 & Aladja & $\mathrm{PQ}$ & 1.0451 & 10.3543 \\
8 & Benin & $\mathrm{PQ}$ & 1.0278 & 6.4591 \\
9 & Ayede & $\mathrm{PQ}$ & 0.9719 & 2.0025 \\
10 & Osogbo & $\mathrm{PQ}$ & 1.0142 & 7.7596 \\
11 & Afam & $\mathrm{PV}$ & 1.0500 & 10.3942 \\
12 & Alaoji & $\mathrm{PQ}$ & 1.0304 & 9.7870 \\
13 & New- & $\mathrm{PQ}$ & 0.9462 & 2.5129 \\
14 & Haven & $\mathrm{PQ}$ & 0.9667 & 3.8964 \\
15 & B Kebbi & $\mathrm{PQ}$ & 1.0328 & 13.8528 \\
16 & Gombe & $\mathrm{PQ}$ & 0.8973 & 3.3762 \\
17 & Jebba & $\mathrm{PQ}$ & 1.0486 & 13.3972 \\
18 & Jebba GS & $\mathrm{PV}$ & 1.0500 & 13.6494 \\
19 & Jos & $\mathrm{PQ}$ & 0.9950 & 10.2653 \\
20 & Kaduna & $\mathrm{PQ}$ & 1.0116 & 6.0096 \\
21 & Kainji & $\mathrm{PV}$ & 1.0500 & 16.5571 \\
22 & Kano & $\mathrm{PQ}$ & 0.9629 & 1.8617 \\
23 & Shiroro & $\mathrm{PV}$ & 1.0500 & 8.0748 \\
24 & Sapele & $\mathrm{PV}$ & 1.0500 & 7.9310 \\
25 & Markurdi & $\mathrm{PQ}$ & 1.0146 & 14.2568 \\
26 & Abuja & $\mathrm{PQ}$ & 1.0266 & 6.0111 \\
27 & Mambilla & $\mathrm{PV}$ & 1.0500 & 26.0437 \\
28 & Papalanto & $\mathrm{PV}$ & 1.0500 & 3.2526 \\
\hline Gest case 2: Elimination of Voltage Limit violation
\end{tabular}

This is similar to test case 1 except that, the SSSC has been installed between buses 19 and 16 for elimination of voltage limit violation at bus 16 (Gombe). 


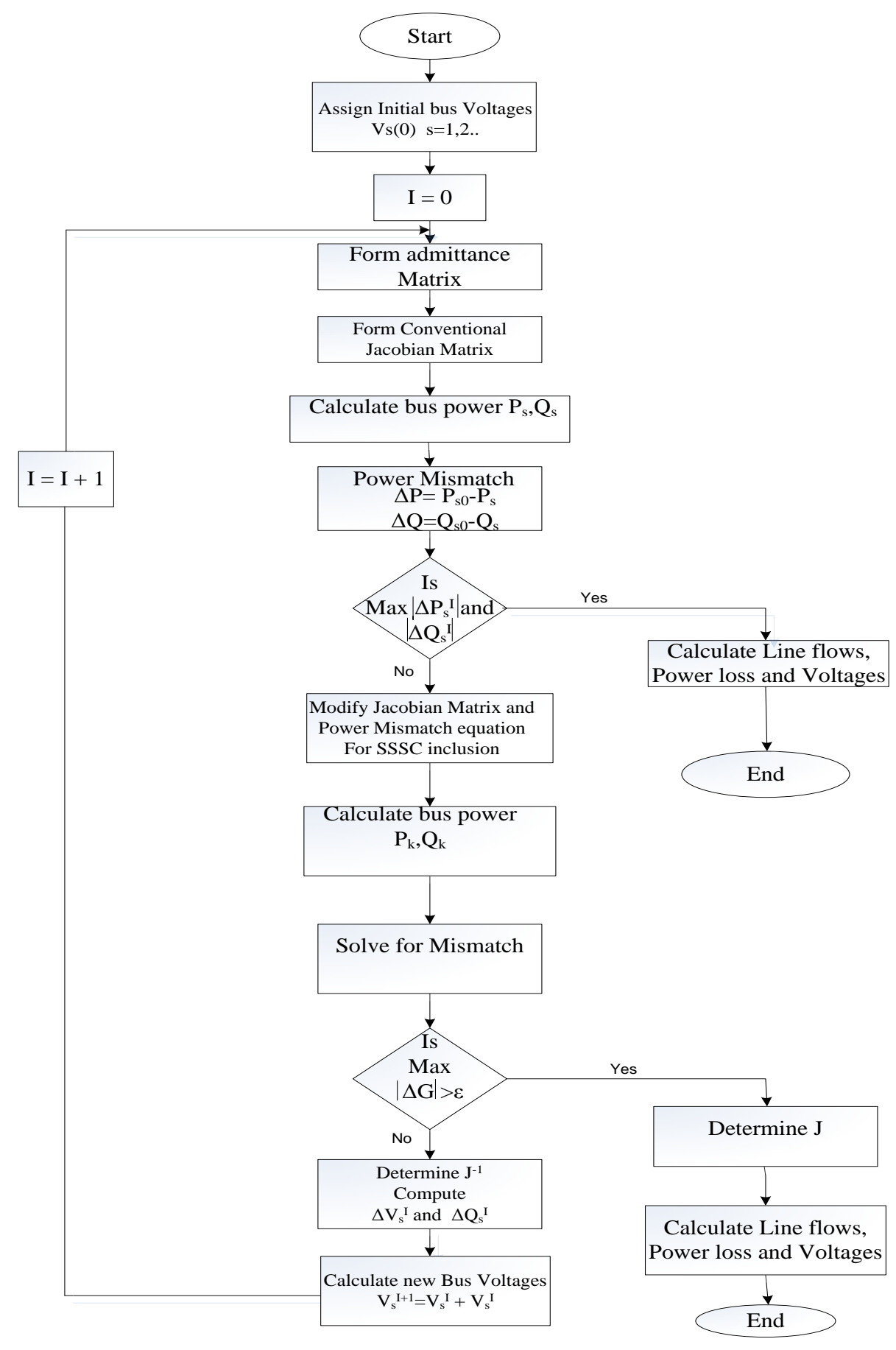

Figure 4: Flowchart for power flow solution by Newton-Raphson with SSSC controller

The results of test case 2 increased the voltage magnitude to 0.95 thereby eliminating voltage limits violation at bus 16 (Gombe) as shown in Figure 5. In order to achieve this the SSSC injected a voltage magnitude and reactive power of 0.012 p.u and 9.53 Mvar in the connecting bus 19 to bus 16 . Also the total active power loss was reduced to $91.43 \mathrm{MW}$. Test case 3: Bus Voltage Control to Specified value
This is similar to test case 1 except that, the SSSC has been installed between buses 8 and 14 to control the bus voltage magnitude to a reference of $V_{14}^{\text {Spec }}=$ 1.0 p.u.

The installation of SSSC controller for test case 2 is for controlling voltage magnitude at bus 14 (Onitsha) to the specified value (1.00 p.u.) as shown in Figure 6. In 
order to keep bus 14 (Onitsha) voltage magnitude at 1.0 p.u., the SSSC injected reactive power of 6.81 Mvar and the total active power loss was reduced to 91.44MW.

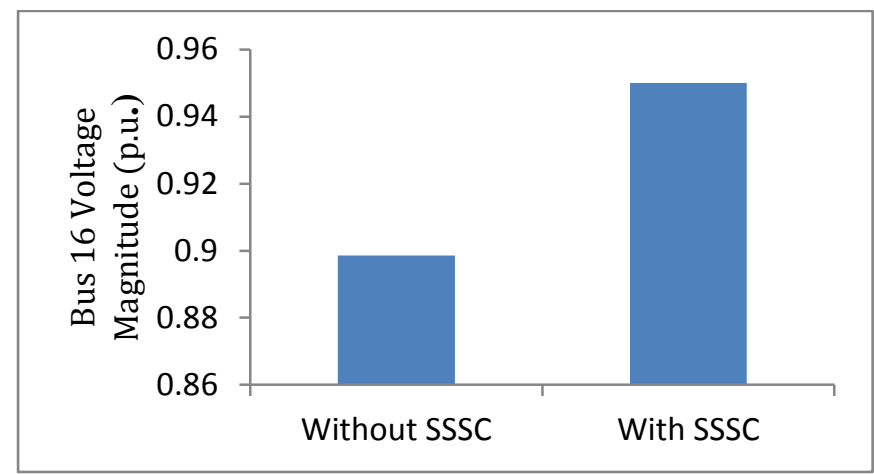

Figure 5: Elimination of Voltage Limit Violation of bus 16 (Gombe) using SSSC Controller

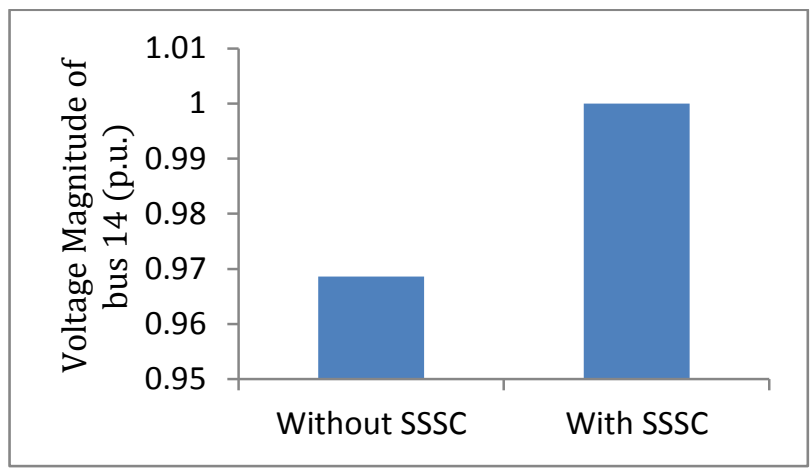

Figure 6: Bus Voltage Control to Specified value at bus 14(Onitsha) using SSSC Controller

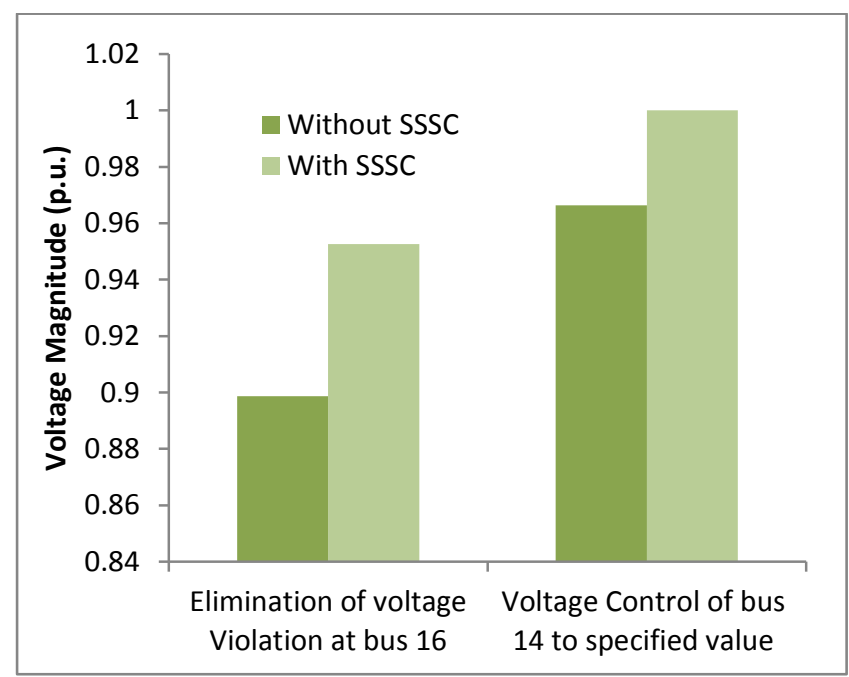

Figure 7: Elimination of Voltage Limits Violation at bus 16 (Gombe) and Control Voltage to Specified value at bus 14(Onitsha) using SSSC Controller

Test case 4: Elimination of Voltage Limit violation and Bus Voltage Control to Specified value

This is similar to case 1 except that there are two SSSCs installed on lines 19 to 16 and 8 to 14, used for eliminating voltage limits violation at bus 16 and control voltage to specified value at bus 14 , for multicontrol capability of SSSC controller.

The results of test obtained was 0.9526 and 1.00 p.u for eliminating voltage limits violation at bus 16 (Gombe) and controlling voltage magnitude at bus 14 (Onitsha) to specified value (1.00 p.u.) respectively, as shown in Figure 7. The results confirmed multi-control capability of SSSC controller. It further enhance the reduction of active power loss to $5.18 \%$ compared with earlier discussed in test cases 2 and 3 as shown in Figure 8. The SSSC controller source voltages and injected reactive power are summarized in Table 2.

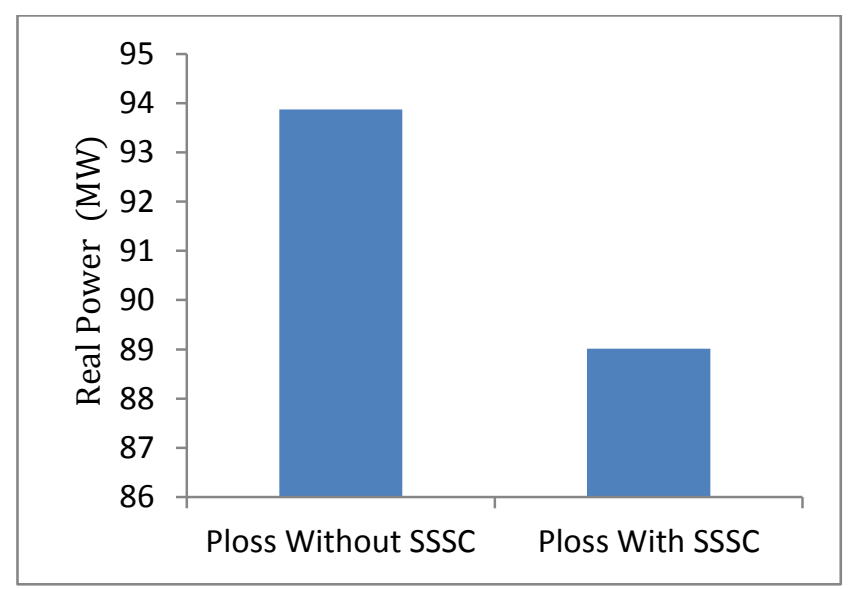

Figure 8: Total Real Power Loss (without and with SSSC) for Nigerian 28-Bus System Network

Table 2: SSSC controllers source voltages and injected powers in Nigerian 28-bus System

\begin{tabular}{cccc}
\hline $\begin{array}{c}\text { Test } \\
\text { Cases }\end{array}$ & $\begin{array}{c}\text { FromTo } \\
\text { BusBus }\end{array}$ & $\begin{array}{c}\text { SSSC state } \\
\text { variables } \\
V_{\text {se }} \text { (p.u.) }\end{array}$ & $\begin{array}{c}\text { SSSC complex } \\
\text { powers } \\
\text { P(MW) Q(Mvar) }\end{array}$ \\
\hline Base & Nil & Nil & Nil Nil \\
2 & 1916 & 0.023 & 0.09 .61 \\
3 & 814 & 0.032 & 0.06 .81 \\
4 & 1916 & 0.012 & 0.09 .53 \\
& 814 & 0.032 & 0.06 .88 \\
\hline
\end{tabular}

\section{CONCLUSION}

The various test cases were carried out on Nigerian 28bus electrical power network without and with incorporation of SSSC controller. The incorporation of SSSC controller into Nigerian $330 \mathrm{kV}$ transmission network, to enhance voltage profile had significant control on Voltage magnitude at the bus directly connected to its terminals but has little effect or no effect on voltage magnitude of bus far away from it. The total active power loss of the system was reduced by more than $5.18 \%$ of the base case.

In conclusion, the application of SSSC controller to Nigerian $330 \mathrm{kV}$ transmission network using NewtonRaphson power flow solution method was used to eliminate bus voltage limit violation and control of bus 
voltage magnitude to specified values without generation rescheduling or topological changes of the system.

\section{REFERENCES}

[1] Acha E., Fuerte-Esquivel C. R., Ambriz-Pe'rez H. and Angeles-Camacho C. "FACTS Modeling and Simulation in Power Flow Analysis", West Sussex, England: John Wiley \& Sons Ltd. 2004.

[2] Gupta, J. B. "A course in Power Systems", New Delhi: S. K. Kataria \& Sons Publishers of Engineering and Computer Books. 2011.

[3] Vakula, P.. "Study the Power Flow Control of a Power System with Unified Power Flow Controller," Unpublish Master Thesis Submitted to California State University, Sacramento, 2010.

[4] Acha E., Agelidis V. G., Anaya-Lara O. and Miller T. "Power Electronics Control in Electrical System", Linacre House Jordan Hil, Oxford: Newnes An Inprint of Butterworth-Heineman. 2002.

[5] Bada A. S. A. "Transmission Evacuation and Constraints," at National Power Sector Retreat, Abuja, Nigeria 2012.

[6] Adepoju G. A., Komolafe O. and Aborisade D. O. "Power Flow Analysis of the Nigerian Transmission System Incorporating Facts Controllers," International Journal of Applied Science and Technology, Volume 1, No. 5, pp. 186-200. 2011.

[7] Hingorani N. G. and Gyugyi L. "Understanding FACTS Concepts and Technology of Flexible $A C$ Transmission Systems", Piscataway, New Jersey: John Wiley \& Sons, Inc. 2000.
[8] Mohsin I. S., Amin S. N. P. and Anas I. S. "SSSC-Static Synchronous Series Compensator: Theory, Modeling Controlling and Voltage Level Improvement of Power System," Journal of Applied Engineering, Volume 2, No. 5. 2014.

[9] Zhang X. P., Rehtanz C. and Pal B. "Flexible $A C$ Transmission Systems: Modelling and Control", New York: Springer. 2006

[10] Onohaebi O. and Apeeh S. T. "Voltage Instability in Electrical Network, A Case Study of the Nigerian $330 \mathrm{kV}$ Transmission Grid", Journal of Engineering and Applied Sciences, Volume 8, No. 2, pp. 865-874. 2007.

[11] Eseosa 0. and Ogujor E. A. "Determination of Bus Voltages, Power Losses and Flows in the Nigeria 330kv Integrated Power System," International Journal of Advances in Engineering \& Technology, Volume 4, No. 1, pp. 94-97. 2012.

[12] Senbajo A. A. and Coker J. O. "An Overview of Integrated Power Supply System Solution to Nigerian's Electricity Problem," Journal of Applied and Natural Science, Volume 5, No. 1, pp. 268-273. 2013.

[13] NCC-TCN "28-Bus Nigerian Power System Networks," Transmission Company of Nigeria, Osogbo. 2014.

[14] Mohammed O. H., Cheng S. J. and Zakaria A. Z. "Steady-State Modelling of SVC and TCSC for Power Flow Analysis," International Multi-Conference of Engineers and Computer Scientists, Hong Kong. 2009.

[15] Saadat H. "Power System Analysis", London: Micrawhill Inc. 2004. 